\title{
Simultaneous detection of chlorinated polycyclic aromatic hydrocarbons with polycyclic aromatic hydrocarbons by gas chromatography-mass spectrometry
}

\author{
Meng Qiao ${ }^{1} \cdot$ Wei Cao $^{1} \cdot{\text { Bochuan } \operatorname{Liu}^{1} \cdot \mathrm{Xu} \mathrm{Zhao}^{1} \cdot \text { Jiuhui Qu }}^{1}$
}

Received: 12 December 2016/Revised: 17 February 2017 / Accepted: 28 February 2017 / Published online: 25 March 2017

(C) Springer-Verlag Berlin Heidelberg 2017

\begin{abstract}
Chlorinated polycyclic aromatic hydrocarbons (ClPAHs), including polychlorinated naphthalenes (PCNs), are hazardous and widespread in the environment, but studies of these substances in the wastewater environment are lacking. In this study, five typical PCNs and five typical ClPAHs (other than PCNs) were simultaneously detected along with their parent polycyclic aromatic hydrocarbons in wastewater samples. All these compounds could be analyzed by gas chromatography- electron ionization mass spectrometry in selected ion monitoring mode and separated on a DB- $17 \mathrm{~ms}$ column. Calibration curves were created both in pure solvent and in wastewater matrix samples. The coefficients of determination for most compounds were greater than 0.99 , indicating a satisfactory degree of linearity in the complex matrix samples. The influence of the matrix on the true concentrations of the environmental samples was corrected by use of the matrix calibration curve. The recoveries of all compounds were between $58 \%$ and $127 \%$, with standard deviations lower than $20 \%$. The method detection and quantification limits were less than $27.6 \mathrm{ng} / \mathrm{L}$ and less than $91.9 \mathrm{ng} / \mathrm{L}$ respectively in the aqueous phase, and less than $0.18 \mathrm{ng} / \mathrm{L}$ and less than $0.61 \mathrm{ng} / \mathrm{L}$ respectively in the solid phase of 4-L wastewater samples. This analytical method was successfully used to detect PCNs and ClPAHs in the water from a river receiving
\end{abstract}

Electronic supplementary material The online version of this article (doi:10.1007/s00216-017-0290-1) contains supplementary material, which is available to authorized users.

Xu Zhao

zhaoxu@ rcees.ac.cn

1 Key Laboratory of Drinking Water Science and Technology, Research Center for Eco-Environmental Sciences, Chinese Academy of Sciences, Beijing 100085, China effluent from a wastewater treatment plant. The concentrations of each compound ranged from 3.1 to $29.6 \mathrm{ng} / \mathrm{L}$. This method could also be used for detection of other polycyclic aromatic hydrocarbon derivatives with similar physical and chemical properties in different matrix samples.

Keywords Chlorinated polycyclic aromatic hydrocarbons . Polychlorinated naphthalenes $\cdot$ Solid-phase extraction . Accelerated solvent extraction $\cdot$ Water matrix

\section{Introduction}

Chlorinated polycyclic aromatic hydrocarbons (ClPAHs), including polychlorinated naphthalenes (PCNs), are chlorinated derivatives of polycyclic aromatic hydrocarbons (PAHs) that are widespread and persistent in the environment [1]. PCNs are industrially synthesized compounds usually used as dielectric fluids, flame retardants, and fungicides. They might also be formed and released into the environment through waste incineration, copper smelting, and chlorine production [2]. ClPAHs (other than PCNs) can be formed from the photochemical and thermal reaction of PAHs, and discharged into the environment through vehicle exhaust, organic matter incineration, and other industrial activities [3]. Compared with the parent PAHs, some of the chlorinated derivatives are more highly mutagenic $[4,5]$. PCNs have been implicated in causing various diseases, such as chloracne, liver damage, $\mathrm{X}$ disease in cattle, and chick edema [2]. Some ClPAHs were found to act as strong mutagens both in the presence and in the absence of metabolic activation, whereas benzo $[a]$ pyrene was found to be the only mutagenically active parent PAH. 9Chlorofluorene showed higher mutagenic activity than other ClPAHs [6]. Thus, it is necessary to focus on PCNs and 
CIPAHs because of the widespread emission sources and hazardous properties.

In general, PCNs and CIPAHs have been analyzed by highresolution gas chromatography (HRGC)-high resolution mass spectrometry (HRMS) and gas chromatography (GC)-mass spectrometry (MS). PCNs have been commonly detected by HRGC-HRMS or GC-MS-MS combined with electron ionization (EI) and separated with a nonpolar fused-silica capillary column such as an Agilent DB-5 column (60 $\mathrm{m} \times 0.25$ $\mathrm{mm}$ inner diameter, $0.25-\mu \mathrm{m}$ film thickness) [2, 7-9]. They have also been analyzed with a GC-MS system equipped with an electron capture negative ion detector and a nonpolar column. The instrument detection limits (IDLs) ranged between 0.0068 and $1.07 \mathrm{ng}$ per sample [10]. GC-EI-MS can be used to determine PCNs. For example, a more polar column, DB1701 (30 $\mathrm{m} \times 0.25$-mm inner diameter, $0.25-\mu \mathrm{m}$ film thickness), connected to a DB-5 column was used for separation and identification of the individual congeners [11]. For CIPAHs, analysis was performed by HRGC-EI-HRMS with a DB-5 column [11, 12] and liquid chromatography-mass spectrometry [13]. ClPAHs, oxygenated PAHs (OPAHs), and PAHs were separated by high-performance liquid chromatography (HPLC) and analyzed by GC-EI-MS with a nonpolar column, SE-54 or DB-5 [14, 15]. For both CIPAHs and PAHs, the isolation was performed with a two-dimensional HPLC system and they were selectively analyzed by GCMS with chemical ionization in negative ion detection mode [16]. CIPAHs and PAHs were simultaneously determined by GC-ion trap EI-MS and separated on a nonpolar column, Rxi$5 \mathrm{MS}(30 \mathrm{~m} \times 0.25-\mathrm{mm}$ inner diameter, $\times 0.25-\mu \mathrm{m}$ film thickness) [17]. ClPAHs and PAHs were also determined by GCEI-MS with an Rxi-5MS column. However, the injector temperatures and the column oven temperature programs were different for CIPAHs and PAHs [18]. Studies have also focused on PCNs, CIPAHs, and PAHs. The analysis of PCNs and CIPAHs was performed by HRGC-EI-HRMS with a DB5ms column, whereas, PAHs were analyzed by GC-MS [19]. Thus, detection of PCNs, CIPAHs, and PAHs with the same instrument and the same procedure could be difficult with the present analytical methods. So, in this study, we intended to develop a method that simultaneous detects PCNs and CIPAHs with PAHs, OPAHs, methyl PAHs (MPAHs), and nitrated PAHs (NPAHs) [20].

Many studies have focused on the determination of these compounds in the atmosphere, soil, sediment, and biota environments, but only a few studies have been conducted in a water environment. ClPAHs, which can be formed during chlorination, have been detected in tap water. The concentrations of 1-chloronaphthalene (1-CN), dichloronaphthalene, 9chlorophenanthrene (9-ClPhe), 3-chlorofluoranthene, and 1chloropyrene ranged from 0.03 to $35 \mathrm{ng} / \mathrm{L}[12,17]$. 9ClPhewas demonstrated to be a main chlorinated PAH byproduct when the $\mathrm{pH}$ was less than 4 during chlorination
$[14,15]$. The concentrations of PCNs were found to be relatively high in surface water and groundwater. The concentrations of 1-CN, 2-chloronaphthalene (2-CN), 1,4dichloronaphthalene (DCN), 2,3,6,7-tetrachloronaphthalene, and octachloronaphthalene $(\mathrm{OCN})$ ranged from 0.1 to $542 \mathrm{ng} / \mathrm{L}$ in a river used for source water [2]. In groundwater, the total PCN concentrations were higher levels, ranging from less than 0.5 to $79 \mu \mathrm{g} / \mathrm{L}$, with 2,3,6,7-tetrachloronaphthalene as the major congener in the group [21]. The concentrations of 1-CN and dichloronaphthalene were $0.01-1.0 \mu \mathrm{g} / \mathrm{L}$ in the upper aquifer layer and $0.09-750 \mu \mathrm{g} / \mathrm{L}$ in the lower layer [22]. Thus, it is clear that the pollution levels of PCNs and ClPAHs differ a great deal in different water matrixes and places. However, previous studies seldom focused on wastewater. Therefore, it is essential to give more attention to these types of pollutants in wastewater systems.

Because of the different lipophilicity of the compounds, the lower molecular ring number PAH chlorinated derivatives are preferentially found in water, whereas the higher molecular ring number derivatives preferentially exist in sediment [1]. Therefore, this study focused on the chlorinated derivatives of lower molecular ring number PAHs, including the PCNs and two to three ring CIPAHs. The aim of this study was to optimize and validate a method for simultaneous determination of the lower molecular ring number chlorinated PAHs along with the parent PAHs and some other types of PAH derivatives in water matrix samples. In the future, both contamination by PCNs and CIPAHs in a water environment and the transformation of PAHs to their chlorinated derivatives during chlorine disinfection water treatment processes could be detected with this method.

\section{Method and materials}

\section{Standards and chemicals}

Five PCN standards-1-CN (in solid form, 95.5\%), 2-CN (100 $\mathrm{gg} / \mathrm{mL}$ in methanol), DCN (solid, 99.4\%), 1,2,3,4tetrachloronaphthalene ( $\mathrm{TeCN}$; solid, 100\%), and $\mathrm{OCN}$ (100 $\mathrm{\mu g} / \mathrm{mL}$ in methanol)—were purchased from AccuStandard (USA). Five CIPAH standards-9-chloro-9Hfluorene (9-ClFluo; $50 \mu \mathrm{g} / \mathrm{mL}$ in isooctane), 9-ClPhe $(50 \mu \mathrm{g} /$ $\mathrm{mL}$ in isooctane), 2-chloroanthrancene (2-ClAnt; $50 \mu \mathrm{g} / \mathrm{mL}$ in isooctane), 1-chloroanthraquinone (1-ClAQ; solid, 98\%), 9,10-dichloroanthracene (9,10-DClAnt; solid, 96\%)-were purchased from Chiron (Norway). The 16 US EPA priority PAHs, four MPAHs, four OPAHs, and five NPAHs (see Table S1) were the same as in a previous study [20]. Internal standards, including 2-fluorobiphenyl (solid, purity greater than 96\%) and decachlorobiphenyl (PCB209) were obtained from Aldrich (UK). 
Hexane (Fisher Scientific, USA), dichloromethane (J.T.Baker, USA), methanol (Fisher Scientific, USA) and acetone (Dikma Technologies, USA) were HPLC grade solvents. Silica gel $(0.06-0.2 \mathrm{~mm})$ and alumina (100-200 mesh) for chromatography were purchased from Acro Organics (USA). Before use, silica gel and alumina were baked at 180 and $250{ }^{\circ} \mathrm{C}$ respectively for $12 \mathrm{~h}$, and then deactivated with $3 \%$ redistilled water, and kept in hexane until use. Analytical grade anhydrous sodium sulfate (Tianjin, China) was baked at $450{ }^{\circ} \mathrm{C}$ for $5 \mathrm{~h}$ before use.

\section{Sampling}

Five real wastewater samples were collected from a river receiving wastewater treatment effluent in Beijing in April and November, 2015 respectively. The 4-L water samples were filtered through glass microfiber filters (Whatman GF/F, $142-\mathrm{mm}$ diameter, $0.7-\mu \mathrm{m}$ pore size). The aqueous-phase samples were stored at $4{ }^{\circ} \mathrm{C}$ and extracted within 2 days. The solid-phase samples (suspended particulates) were stored in a refrigerator at $-20^{\circ} \mathrm{C}$, and freeze-dried before analysis.

\section{Pretreatment procedure}

Aqueous-phase samples were extracted with $\mathrm{C}_{18}$ columns (500 mg, $6 \mathrm{~mL}$, Supelco) by the solid-phase extraction (SPE) method. Before use, the columns were activated with $5 \mathrm{~mL}$ dichloromethane, $5 \mathrm{~mL}$ methanol, and $5 \mathrm{~mL}$ pure water successively. After $4 \mathrm{~L}$ water extraction, the contents of the $\mathrm{C}_{18}$ columns were eluted with $10 \mathrm{~mL}$ dichloromethane and $5 \mathrm{~mL}$ hexane continuously. Solidphase samples were extracted by the accelerated solvent extraction (ASE300, Donex) method with 1:1 dichloromethane -acetone. The extraction temperature was $120{ }^{\circ} \mathrm{C}$, and the pressure was 1500 psi. The step was repeated twice. The extracts from both SPE and accelerated solvent extraction were concentrated and the solvent was changed to hexane. Then, the silica gel-alumina packed columns (12-cm silica gel, 6-cm alumina, and 2$\mathrm{cm}$ sodium sulfate) were used for purification od the complex matrix samples. The eluted fractions were concentrated to $0.5 \mathrm{~mL}$, and internal standards were added before instrumental analysis.

\section{GC-MS analysis}

An Agilent 7890A gas chromatograph equipped with a 5795C mass detector with an electron impact source was used for detection of the targets. A DB-17ms fused-silica capillary column $(30 \mathrm{~m}$ length $\times 0.25-\mathrm{mm}$ diameter $\times$ $0.25-\mu \mathrm{m}$ film thickness) was used for separation of the compounds. Samples $(1 \mu \mathrm{L})$ were injected in splitless mode. The carrier gas was helium. The injector and source temperatures were kept at 280 and $290{ }^{\circ} \mathrm{C}$ respectively. The temperature program was as follows: $60{ }^{\circ} \mathrm{C}$ (held for $1 \mathrm{~min}$ ), heated to $110{ }^{\circ} \mathrm{C}$ at a rate of $20{ }^{\circ} \mathrm{C} /$ min, and heated to $290{ }^{\circ} \mathrm{C}$ at $3{ }^{\circ} \mathrm{C} / \mathrm{min}$ (held for $20 \mathrm{~min}$ ).

A mixed standard $(1000 \mu \mathrm{g} / \mathrm{L})$ was first analyzed in full-scan mode $(m / z, 50-500)$ for the identification of the quantification ion, confirmation ion, and retention time of each compound. For the selected ion monitoring (SIM) mode, the chromatogram was divided into several retention time windows on the basis of the results with the fullscan mode. For each compound, quantification and confirmation ions were used for qualitative analysis and quantification ions were used for quantitative analysis (Table S1).

\section{Method characterization}

Seven-point calibration curves were established in pure solvent and $4 \mathrm{~L}$ wastewater samples on the basis of the internal standard method. The calibration concentrations ranged from 10 to $1000 \mu \mathrm{g} / \mathrm{L}$. The $10,20,50,100,200,500$, and $1000 \mu \mathrm{g} / \mathrm{L}$ standards were added to the pure solvent and $4 \mathrm{~L}$ wastewater matrix samples. The concentrations for the calibration curve, $C_{\text {cal }}$, in the wastewater matrix samples were calculated as follows:

$C_{\mathrm{cal}}=C_{\mathrm{tot}}-C_{\mathrm{sam}}$,

where $C_{\text {tot }}$ is the concentration measured in the spiked wastewater samples and $C_{\text {sam }}$ is the concentration measured in the nonspiked wastewater samples.

The recoveries were determined for the extraction procedure, the purification procedure, and the whole procedure in the wastewater matrix samples. The method detection limits (MDLs) and method quantification limits (MQLs) were calculated on the basis of three times and ten times the signal-to-noise ratio respectively.

\section{Results and discussion}

On the basis of the method we developed previously [20], five typical PCNs and five typical ClPAHs were adopted as the target compounds.

\section{GC-MS method development}

The GC-MS chromatograms for the 39 substituted PAHs and PAHs and the two internal standards are shown in Fig. 1. The results show that the five PCNs and five CIPAHs could be detected simultaneously along with the 16 PAHs, 4 MPAHs, 4 OPAHs, and 5 NPAHs by GC-EI-MS in SIM mode and with a DB-17ms column. 
Abundance

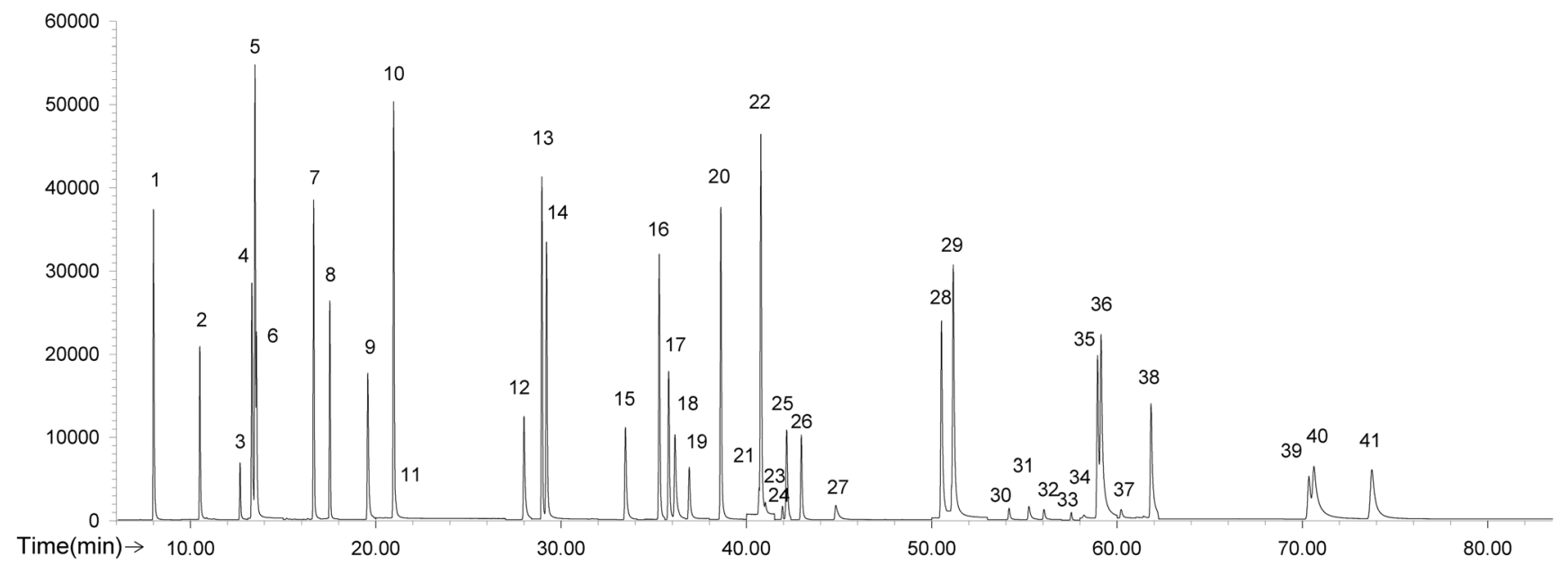

Fig. 1 Gas chromatography-mass spectrometry chromatogram for 23 substituted polycyclic aromatic hydrocarbons, 16 polycyclic aromatic hydrocarbons, and two internal standards. 1 naphthalene, 22 methylnaphthalene, 3 2-fluorobiphenyl, 4 2-chloronaphthalene, 5 2,6dimethylnaphthalene, 61 -chloronaphthalene, 7 acenaphthylene, 8 acenaphthene, 9 1,4-dichloronaphthalene, 10 fluorene, 11 9-chloro-9Hfluorene, 12 9-fluorenone, 13 phenanthrene, 14 anthracene, 15 1,2,3,4tetrachloronaphthalene, 16 3,6-dimethylphenanthrene, 17 9chlorophenanthrene, 18 2-chloroanthracene, 19 anthraquinone, 20

fluoranthene, 21 2-methylanthraquinone, 22 pyrene, 23 2-nitrofluorene, 24 9-nitroanthracene, 25 9,10-dichloroanthracene, 261 methylfluoranthene, 27 1-chloroanthraquinone, 28 benz $[a]$ anthracene, 29 chrysene, 30 3-nitrofluoranthene, 31 benz [ $a]$ anthrancene-7,12-dione, 32 1-nitropyrene, 33 decachlorobiphenyl, 34 octachloronaphthalene, 35 benzo[b]fluoranthene, 36 benzo[k]fluoranthene, 377 nitrobenz $[a]$ anthracene, 38 benzo[ $a]$ pyrene, 39 indeno[ $[1,2,3-c d]$ pyrene, 40 dibenz $[a, h]$ anthracene, 41 benzo $[g, h, i]$ perylene, SIM selected ion monitoring

However, some peaks overlapped in the chromatogram when separated by the DB-17ms column, such as peaks 4,5 , and 6 (corresponding to 2-CN, 2,6dimethylnaphthalene, and 1-CN) and peaks 21,22 , and 23 (corresponding to 2-methylanthraquinone, pyrene and 2-nitrofluorene). With SIM mode, when ions 162, 156, 222,202 , and 211 were extracted, the six compounds could be cleanly separated.

It has also been reported that PCNs and CIPAHs could be determined with a DB-5ms column $[7,11,15]$. So we compared the DB- $5 \mathrm{~ms}$ column with the DB- $17 \mathrm{~ms}$ column to evaluate the IDLs (Table 1). For most of the compounds, especially the higher molecular weight ones, the IDLs were two to three times lower when the DB$17 \mathrm{~ms}$ column was used than when the DB- $5 \mathrm{~ms}$ column was used. For the other compounds, when the DB- $17 \mathrm{~ms}$ column was used, the IDLs were similar to or a little lower than those obtained with the DB-5ms column. This might be due to the different polarities of the two columns. The responses (peak areas) of PCNs and ClPAHs were higher with the more polar DB- $17 \mathrm{~ms}$ column. The instrument noise values were similar with the DB- $17 \mathrm{~ms}$ and DB-5ms columns. Thus, the higher response and similar noise resulted in lower IDLs. As a result, the DB- $17 \mathrm{~ms}$ column was better than the DB$5 \mathrm{~ms}$ column for determining the five PCNs and five CIPAHs from the aspect of the IDLs.

\section{Extraction}

\section{Solid-phase extraction}

The target compounds in the aqueous-phase samples were extracted with the $\mathrm{C}_{18}$ columns. The details of the extraction procedure are given in "Pretreatment procedure." The

Table 1 Instrument detection limits obtained with the DB-17ms and DB-5ms columns

\begin{tabular}{lll}
\hline \multirow{2}{*}{ Compound } & \multicolumn{2}{l}{$\mathrm{IDL}(\mathrm{ng})$} \\
\cline { 2 - 3 } & $\mathrm{DB}-17 \mathrm{~ms}$ & $\mathrm{DB}-5 \mathrm{~ms}$ \\
\hline 2-Chloronaphthalene & 1.5 & 1.5 \\
1-Chloronaphthalene & 1.5 & 2.0 \\
1,4-Dichloronaphthalene & 0.5 & 0.5 \\
1,2,3,4-Tetrachloronaphthalene & 0.5 & 1.0 \\
Octachloronaphthalene & 1.0 & 3.0 \\
9-Chloro-9H-fluorene & 3.0 & 2.0 \\
9-Chlorophenanthrene & 0.5 & 0.5 \\
2-Chloroanthracene & 0.5 & 1.0 \\
9,10-Dichloroanthracene & 0.5 & 1.0 \\
1-Chloroanthraquinone & 2.5 & 5.0 \\
\hline
\end{tabular}

$I D L$ instrument detection limit 
$\mathrm{C}_{18}$ column can not only extract the target compounds but can also purify environmental samples for which the matrix is not very complicated, such as tap water.

The recoveries of the ten compounds ranged from $46 \%$ to $113 \%$ (Fig. 2). For PCNs, the recoveries of $1-\mathrm{CN}$ and $2 \mathrm{CN}$ were between $46 \%$ and $48 \%$, and the recovery of DCN was $72 \%$, lower than the US EPA recommended recovery standard $(80-120 \%)$, while the recoveries of $\mathrm{TeCN}$ and OCN were $99 \%$ and $108 \%$ respectively, meeting the standard. The volatility of the compounds decreased with increasing chlorine numbers [23, 24]. Similar results were obtained by Pizzini et al. [8]. The evacuation step during the SPE procedure might accelerate the volatilization of the low chlorine number PCNs, resulting in the lower recoveries of $2-\mathrm{CN}, 1-\mathrm{CN}$, and DCN. For ClPAHs, the recovery of 9-ClFluo was $65 \%$, whereas the recoveries of the other four ClPAHs were between $109 \%$ and $113 \%$.

All the compound recoveries were tested in triplicate. The standard deviations for each compound were between $4 \%$ and $18 \%$, indicating an acceptable repeatability for the SPE method. Thus, although the recoveries of 2-CN, 1$\mathrm{CN}$, DCN, and 9-ClFluo were lower than the US EPA standards, the concentrations of these compounds could be corrected with the repeatable recovery values in the real samples. In the complex matrix samples, the lower recoveries could be compensated for by use of the matrix calibration curve, described in "Matrix effect."

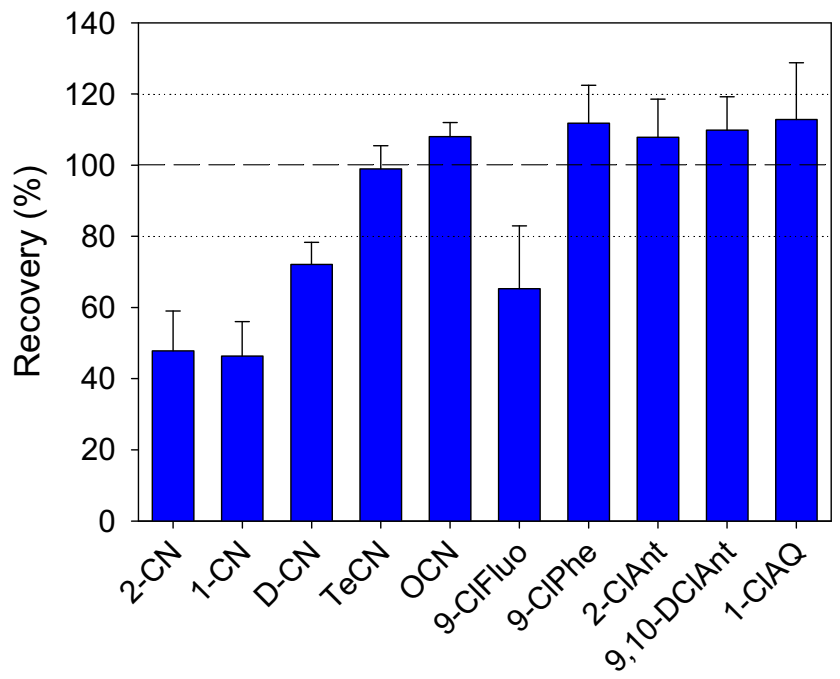

Fig. 2 Recoveries of five polychlorinated naphthalenes (PCNs) and five chlorinated polycyclic aromatic hydrocarbons (CIPAHs) during the soldphase extraction procedure. 2-CN 2-chloronaphthalene, 1-CN 1chloronaphthalene, $D-C N$ 1,4-dichloronaphthalene, $T e C N$ 1,2,3,4tetrachloronaphthalene, OCN octachloronaphthalene, 9-ClFluo 9chloro-9H-fluorene, 9-ClPhe 9-chlorophenanthrene, 2-ClAnt 2chloroanthracene, 9,10-DClAnt 9,10-dichloroanthracene, 1-ClAQ 1chloroanthraquinone

\section{Accelerated solvent extraction}

The target compounds in solid-phase samples were extracted by accelerated solvent extraction. The recoveries of most of the target compounds were between $80 \%$ and $105 \%$, except for OCN $(180 \%)$ and 9-ClFluo (62\%) (Fig. 3). The repeatability of the method was satisfactory. The standard deviations for the compounds were between $2 \%$ and $8 \%$. Similarly to in the SPE procedure, although the recovery of OCN was higher and that of 9-ClFluo was lower, the concentrations in the real samples could be corrected with use of the recoveries or the matrix calibration curve.

\section{Purification}

Considering the different polarities of the target compounds, different solvents were used for elution during the silica gel-alumina purification procedure. Fraction 1 was $10 \mathrm{~mL}$ hexane, fraction 2 was $70 \mathrm{~mL} \mathrm{3:7} \mathrm{dichloro-}$ methane and hexane, fraction 3 was $60 \mathrm{~mL} \mathrm{1:1} \mathrm{dichloro-}$ methane and hexane, and fraction 4 was $60 \mathrm{~mL} \mathrm{7:3} \mathrm{di-}$ chloromethane and hexane. All the compounds except 1ClAQ were eluted in fraction 2, similarly to the PAHs, MPAHs and NPAHs [20]. Because of its higher polarity, 1-ClAQ was mainly found in fractions 3 and 4, similarly to 9-Fluorenone, anthraquinone, and 2 methylanthraquinone [20]. The recoveries of all the compounds ranged from $69 \%$ to $103 \%$ (Fig. 4). The standard deviations ranged from $7 \%$ to $15 \%$.

As a result, the five PCNs and five ClPAHs could be simultaneously extracted and purified with the 16 PAHs, 4 MPAHs, 4 OPAHs, and 5 NPAHs [20].

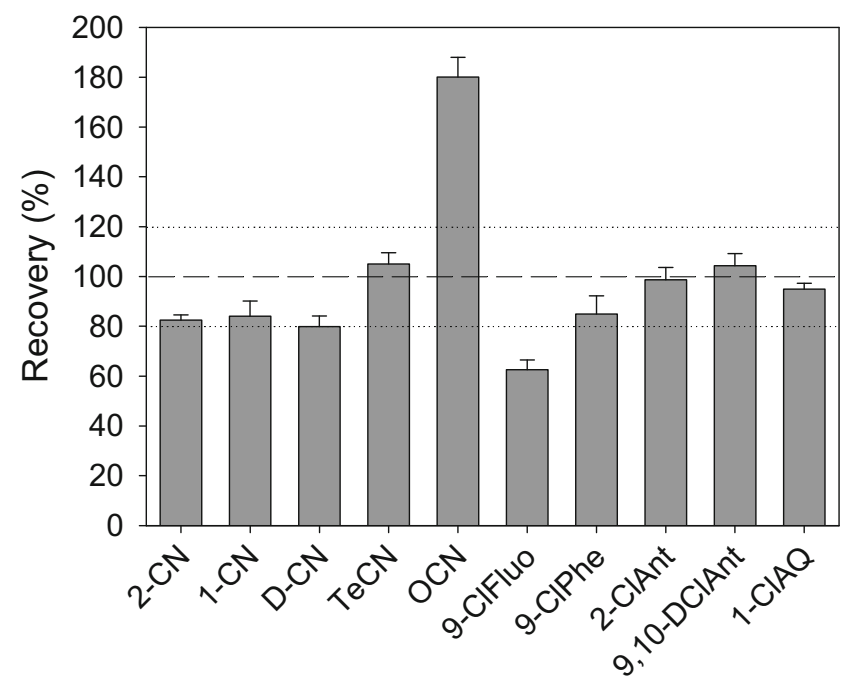

Fig. 3 Recoveries of five PCNs and five ClPAHs during the accelerated solvent extraction procedure 


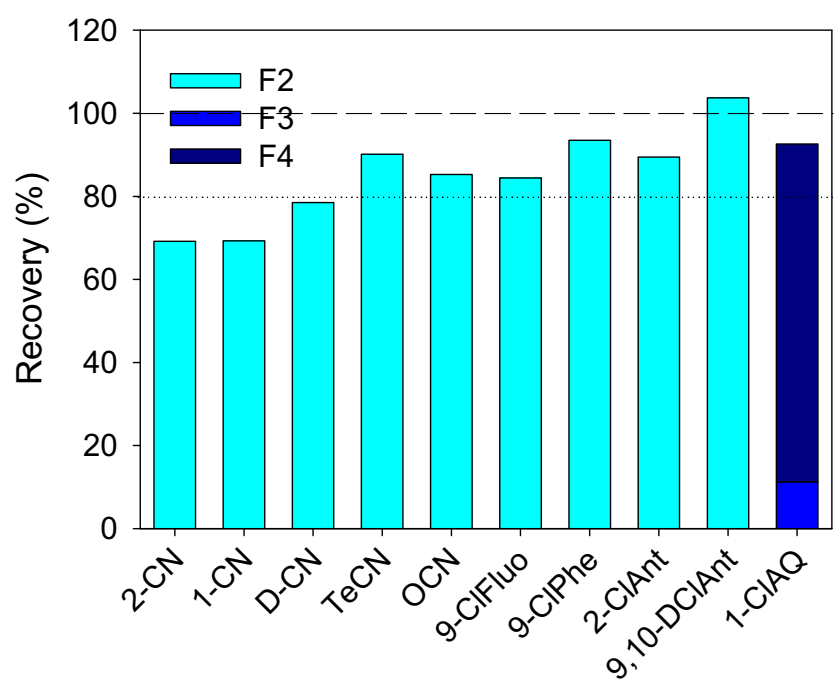

Fig. 4 Recoveries of five PCNs and five ClPAHs in different fractions during the purification procedure. $F 2$ fraction $2, F 3$ fraction $3, F 4$ fraction 4

\section{Matrix effect}

The linearity range, coefficient of determination $\left(R^{2}\right)$, and slope of the calibration curve for the target compounds in the solvent and $4 \mathrm{~L}$ wastewater matrix samples were determined (Table 2). The linearity ranges for the target compounds were between 10 and $1000 \mu \mathrm{g} / \mathrm{L}$ and between 50 and $1000 \mu \mathrm{g} / \mathrm{L}$ for different compounds. On the basis of the linearity range for the target compounds, the linearity ranges for the $4 \mathrm{~L}$ spiking samples were between 1.25 and $125 \mathrm{ng} / \mathrm{L}$ and between 25 and $125 \mathrm{ng} / \mathrm{L}$. The $R^{2}$ values of the target compounds in the solvent samples were all greater than 0.99 . The $R^{2}$ values of most (more than $80 \%$ ) of the compounds in the spiked wastewater samples were greater 0.99 , and the $R^{2}$ values of the other compounds ranged from 0.97 to 0.98 . The concentrations of 9-ClFluo could not be determined in the wastewater matrix samples because of the overlap of its peak with an unknown peak from the matrix.

The ratio between the wastewater slope and the solvent slope was calculated. Generally speaking, the slopes of the calibration curves for all the compounds in the wastewater aqueous-phase spiked samples (0.00002-0.0019) were lower than those in the solvent samples $(0.0002-$ 0.0037), which corresponded to the loss of the compounds during the pretreatment procedure. Some of the slopes for the wastewater solid-phase spiked samples

Table 2 Linearity range, coefficient of determination $\left(R^{2}\right)$,and slope of the calibration curve for target compounds in solvent and 4-L spiked wastewater matrix samples and recoveries in wastewater calculated with the matrix calibration curves

\begin{tabular}{|c|c|c|c|c|c|c|c|c|}
\hline \multirow[t]{2}{*}{ Phase } & \multirow[t]{2}{*}{ Compound } & \multicolumn{2}{|c|}{ Linearity range } & \multicolumn{2}{|l|}{$R^{2}$} & \multicolumn{2}{|l|}{ Slope } & \multirow{2}{*}{$\begin{array}{l}\text { Recovery in wastewater } \\
(\%)\end{array}$} \\
\hline & & $\begin{array}{l}\text { Solvent } \\
(\mu \mathrm{g} / \mathrm{L})\end{array}$ & $\begin{array}{l}\text { Wastewater (ng/ } \\
\text { L) }\end{array}$ & Solvent & Wastewater & Solvent & Wastewater & \\
\hline \multirow[t]{10}{*}{ Aqueous } & 2-Chloronaphthalene & $10-1000$ & $6.25-125$ & 0.99 & 1.00 & 0.0012 & 0.0003 & $94 \pm 13$ \\
\hline & 1-Chloronaphthalene & $10-1000$ & $6.25-125$ & 0.99 & 1.00 & 0.0012 & 0.0002 & $118 \pm 16$ \\
\hline & 1,4-Dichloronaphthalene & $10-1000$ & $2.5-125$ & 0.99 & 0.99 & 0.0042 & 0.0015 & $83 \pm 11$ \\
\hline & 1,2,3,4-Tetrachloronaphthalene & $10-1000$ & $2.5-125$ & 1.00 & 0.99 & 0.0037 & 0.0017 & $82 \pm 13$ \\
\hline & Octachloronaphthalene & $50-1000$ & $25-125$ & 0.99 & 0.97 & 0.0002 & 0.00002 & $101 \pm 20$ \\
\hline & 9-Chloro-9H-fluorene & $50-1000$ & $-^{\mathrm{a}}$ & 0.99 & $-^{\mathrm{a}}$ & 0.0005 & $-^{\mathrm{a}}$ & $-^{\mathrm{a}}$ \\
\hline & 9-Chlorophenanthrene & $10-1000$ & $6.25-125$ & 1.00 & 1.00 & 0.0035 & 0.0019 & $93 \pm 9$ \\
\hline & 2-Chloroanthracene & $20-1000$ & $6.25-125$ & 0.99 & 0.98 & 0.0023 & 0.0016 & $58 \pm 11$ \\
\hline & 9,10-Dichloroanthracene & $20-1000$ & $2.5-125$ & 0.99 & 0.99 & 0.0021 & 0.0008 & $75 \pm 3$ \\
\hline & 1-Chloroanthraquinone & $50-1000$ & $25-125$ & 0.99 & 0.98 & 0.0006 & 0.0002 & $127 \pm 20$ \\
\hline \multirow[t]{10}{*}{ Solid } & 2-Chloronaphthalene & $10-1000$ & $6.25-125$ & 0.99 & 0.99 & 0.0012 & 0.0009 & $101 \pm 17$ \\
\hline & 1-Chloronaphthalene & $10-1000$ & $6.25-125$ & 0.99 & 0.99 & 0.0012 & 0.0007 & $107 \pm 17$ \\
\hline & 1,4-Dichloronaphthalene & $10-1000$ & $2.5-125$ & 1.00 & 0.99 & 0.0042 & 0.0029 & $99 \pm 16$ \\
\hline & 1,2,3,4-Tetrachloronaphthalene & $10-1000$ & $2.5-125$ & 1.00 & 0.99 & 0.0037 & 0.0035 & $90 \pm 11$ \\
\hline & Octachloronaphthalene & $50-1000$ & $2.5-125$ & 0.99 & 1.00 & 0.0002 & 0.0004 & $77 \pm 12$ \\
\hline & 9-Chloro-9H-fluorene & $50-1000$ & $-^{\mathrm{a}}$ & 0.99 & $-^{\mathrm{a}}$ & 0.0005 & $-^{\mathrm{a}}$ & $-^{a}$ \\
\hline & 9-Chlorophenanthrene & $10-1000$ & $6.25-125$ & 1.00 & 1.00 & 0.0035 & 0.0035 & $108 \pm 13$ \\
\hline & 2-Chloroanthracene & $20-1000$ & $1.25-125$ & 0.99 & 1.00 & 0.0023 & 0.0036 & $87 \pm 19$ \\
\hline & 9,10-Dichloroanthracene & $20-1000$ & $1.25-125$ & 0.99 & 1.00 & 0.0021 & 0.0031 & $107 \pm 19$ \\
\hline & 1-Chloroanthraquinone & $50-1000$ & $1.25-125$ & 0.99 & 0.99 & 0.0006 & 0.001 & $116 \pm 12$ \\
\hline
\end{tabular}

${ }^{a}$ Not determined because of the overlap of the peak with an unknown peak in the matrix 
Table 3 Method detection and quantification limits, and laboratory background concentrations of polychlorinated naphthalenes and chlorinated polycyclic aromatic hydrocarbons

\begin{tabular}{|c|c|c|c|c|c|c|}
\hline \multirow[t]{2}{*}{ Compound } & \multicolumn{3}{|c|}{ Aqueous phase } & \multicolumn{3}{|c|}{ Solid phase } \\
\hline & $\begin{array}{l}\mathrm{MDL} \\
(\mathrm{ng} / \mathrm{L})\end{array}$ & $\begin{array}{l}\mathrm{MQL} \\
(\mathrm{ng} / \mathrm{L})\end{array}$ & $\begin{array}{l}\text { Background } \\
(\mathrm{ng} / \mathrm{L})\end{array}$ & $\begin{array}{l}\mathrm{MDL} \\
(\mathrm{ng} / \mathrm{L})\end{array}$ & $\begin{array}{l}\text { MQL } \\
\text { (ng/L) }\end{array}$ & $\begin{array}{l}\text { Background } \\
(\mathrm{ng} / \mathrm{L})\end{array}$ \\
\hline 2-Chloronaphthalene & 0.74 & 2.45 & ND & 0.10 & 0.33 & 1.0 \\
\hline 1-Chloronaphthalene & 1.62 & 5.41 & ND & 0.18 & 0.61 & ND \\
\hline 1,4-Dichloronaphthalene & 0.10 & 0.34 & $<\mathrm{MQL}$ & 0.04 & 0.12 & 0.5 \\
\hline 1,2,3,4-Tetrachloronaphthalene & 0.07 & 0.24 & ND & 0.02 & 0.07 & ND \\
\hline Octachloronaphthalene & 27.6 & 91.9 & ND & 0.01 & 0.04 & ND \\
\hline 9-Chloro-9H-fluorene & $-^{\mathrm{a}}$ & $-{ }^{\mathrm{a}}$ & $-{ }^{\mathrm{a}}$ & $-{ }^{\mathrm{a}}$ & $-^{\mathrm{a}}$ & $-^{\mathrm{a}}$ \\
\hline 9-Chlorophenanthrene & 0.05 & 0.17 & 0.4 & 0.02 & 0.07 & ND \\
\hline 2-Chloroanthracene & 0.05 & 0.15 & ND & 0.01 & 0.05 & ND \\
\hline 9,10-Dichloroanthracene & 0.21 & 0.69 & ND & 0.02 & 0.05 & ND \\
\hline 1-Cnloroanthraquinone & 0.84 & 2.78 & ND & 0.04 & 0.15 & $<\mathrm{MQL}$ \\
\hline
\end{tabular}

$M D L$ method detection limit, $M Q L$ method quantification limit, $N D$ not detected

${ }^{\mathrm{a}}$ Not determined because of the overlap of the peak with an unknown peak in the matrix were higher than those for the solvent (OCN and most ClPAHs), which might have resulted from the enhanced signal in the complex matrix samples. The intercept for all the calibration curves was set as 0 . Thus, the ratios should be correlated to the recoveries of the compounds. Our results showed that the ratios between the wastewater slope and the solvent slope had a good linear correlation with the recoveries calculated with the solvent calibration curve $\left(R^{2}=0.92\right)$ (Table S2). In addition, the coefficients of determination for the matrix calibration were satisfactory. Therefore, the matrix calibration curve could be used to calculate the concentration in the real water samples. In this way, the influence of the matrix [25] on the true concentration in the real samples could be corrected.

\section{Method performance}

\section{Recoveries for the pretreatment procedure}

The recoveries of the nine compounds (except 9-ClFluo) calculated with the matrix calibration curve in the wastewater matrix samples were almost all between $75 \%$ and $118 \%$, except for 2-ClAnt (58\%) and 1-ClAQ (127\%) in the aqueous phase (Table 2). Five different spiking concentrations were used for recovery determination in the matrix samples. The standard deviations of the compounds were lower than $20 \%$, indicating an acceptable stability. The recoveries for each compound did not significantly differ from $100 \%$ (one-sample $t$ test, $P>0.05)$. Thus, the calibration curve for the spiked
Table 4 Detection rates and concentrations of polychlorinated naphthalenes and chlorinated polycyclic aromatic hydrocarbons in five real wastewater samples

\begin{tabular}{llllll}
\hline \multirow{2}{*}{ Compound } & \multicolumn{2}{l}{ Detection rate $(\%)$} & & \multicolumn{2}{l}{ Concentration (ng/L) } \\
\cline { 2 - 3 } \cline { 5 - 6 } & Aqueous & Solid & & Aqueous & Solid \\
\hline 2-Chloronaphthalene & 100 & 100 & & $13.4-29.9$ & $11.2-16.9$ \\
1-Chloronaphthalene & 0 & 0 & & ND & ND \\
1,4-Dichloronaphthalene & 100 & 100 & & $3.2-8.3$ & $3.9-4.7$ \\
1,2,3,4-Tetrachloronaphthalene & 0 & 0 & & ND & ND \\
Octachloronaphthalene & 0 & 0 & & ND & ND \\
9-Chloro-9H-fluorene & $-{ }^{a}$ & $-{ }^{a}$ & & $-{ }^{a}$ & $-{ }^{a}$ \\
9-Chlorophenanthrene & 100 & 100 & & $7.3-8.3$ & $3.4-4.5$ \\
2-Chloroanthracene & 100 & 80 & & $7.7-9.9$ & ND to 4.3 \\
9,10-Dichloroanthracene & 30 & 0 & & ND to 11.8 & ND \\
1-Chloroanthraquinone & 100 & 100 & & $23.3-30.4$ & $4.2-5.3$ \\
\hline
\end{tabular}

ND not detected

${ }^{\text {a }}$ Not determined because of the overlap of the peak with an unknown peak in the matrix 
matrix samples discussed in the previous section could be used regardless of the influence of the matrix effect.

\section{MDLs, MQLs, and laboratory background conditions}

The MDLs and MQLs in the aqueous-phase samples were $0.05-27.6 \mathrm{ng} / \mathrm{L}$ and $0.15-91.9 \mathrm{ng} / \mathrm{L}$ respectively. In the solid-phase samples, the MDLs and MQLs ranged from 0.01 to $0.18 \mathrm{ng} / \mathrm{L}$ and from 0.04 to $0.61 \mathrm{ng} / \mathrm{L}$ respectively (Table 3 ).

In the aqueous phase, only the concentration of 9-ClPhe in blank samples (deionized water) was above the MQL, $0.4 \mathrm{ng} /$ L. In the solid phase, the laboratory background concentrations of 2-CN and DCN were 1.0 and $0.5 \mathrm{ng} / \mathrm{L}$ respectively, and those of the other compounds were below the MQLs (Table 3).
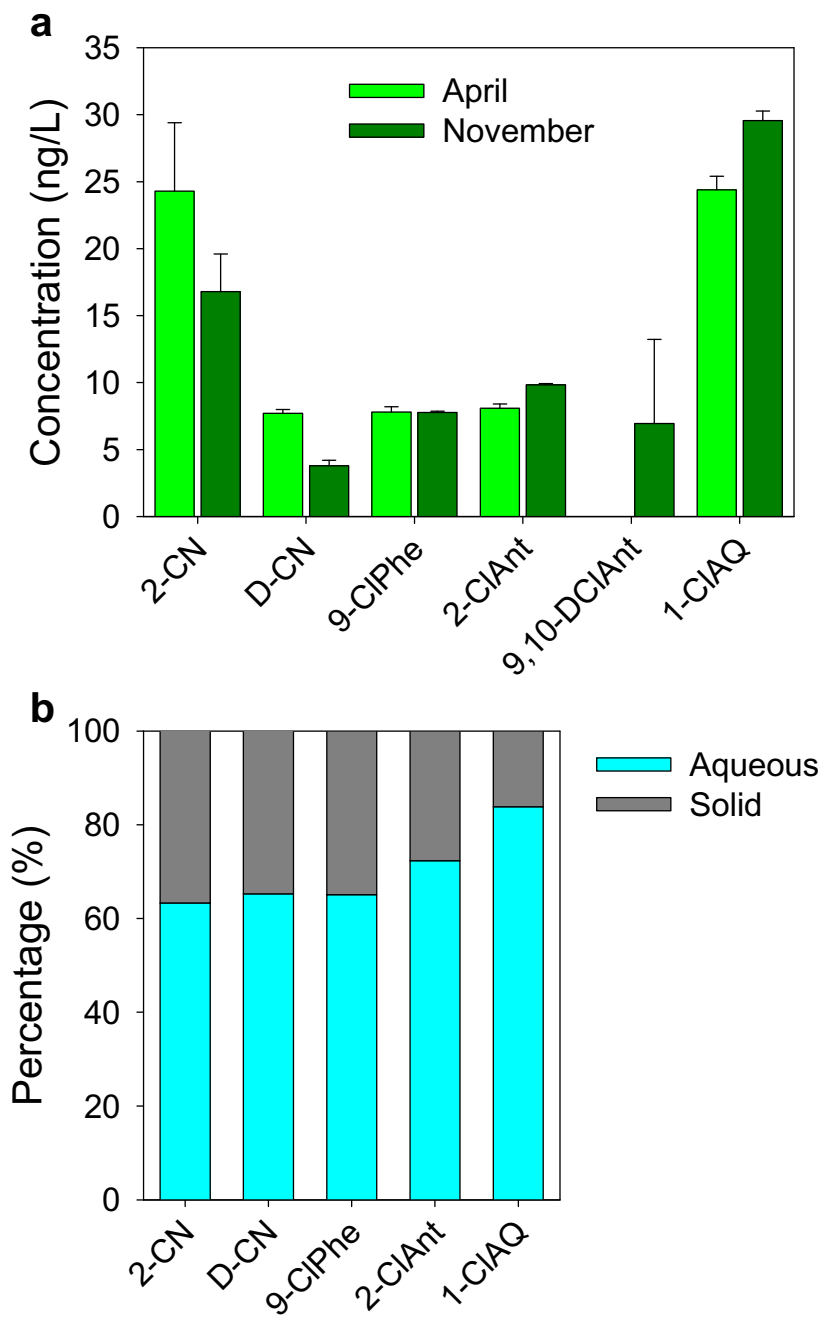

Fig. 5 a Concentrations of PCNs and ClPAHs in April and November. b Distribution of PCNs and CIPAHs in aqueous-phase and solid-phase samples

\section{Application of the method to real water samples}

The five PCNs and five CIPAHs in five water samples from a river receiving wastewater treatment plant effluent were measured. 2-CN, DCN, 9-ClPhe, and 1-ClAQ were detected at a rate of $100 \%$ both in the aqueous-phase and in the solid-phase samples, whereas 1-CN, TeCN, and OCN were not found in the aqueous-phase and solid-phase samples. The concentration ranges of each compound are listed in Table 4.

The average concentrations of the detectable compounds ranged from 3.8 to $29.6 \mathrm{ng} / \mathrm{L}$ in the aqueous-phase samples and from $3.1 \mathrm{ng} / \mathrm{L}$ to 14.1 in the solid-phase samples (Fig. 5a). Compared with those in April, the concentrations of the ClPAHs (2-ClAnt, 9,10-DClAnt, and 1-ClAQ) were higher in November, possibly resulting from a higher emission of CIPAHs in the heating season (November) than the nonheating season (April). However, the concentrations of the PCNs (2-CN and DCN) were higher in April than in November.

From comparison of the contributions of each compound in the aqueous-phase and solid-phase samples, the detectable PCNs and ClPAHs were more prone to exist in the aqueous samples (more than 50\%). (Fig. 5b). The $\log K_{\text {ow }}$ values of the ten compounds were all greater 3.0. The lower concentration in the solid-phase samples might have resulted from the low content of particulates in the wastewater samples.

\section{Conclusion}

The simultaneous detection of five typical PCNs and five typical ClPAHs was accomplished along with the 16 priority PAHs, 4 MPAHs, 4 OPAHs, and 5 NPAHs during the same pretreatment and instrumental analysis procedure. The recoveries of the five PCNs and five ClPAHs during the extraction procedure ranged from $46 \%$ to $180 \%$. The standard deviations were lower than $18 \%$ for each compound, indicating good stability. For the purification procedure, the recoveries of the 10 compounds were between $69 \%$ and $103 \%$, with standard deviations lower than $15 \%$.

With this method, the true concentrations in the real aqueous-phase and solid-phase samples could be calculated with use of the matrix calibration curve, correcting the lower or higher recoveries. The recoveries of all the compounds were between $58 \%$ and $127 \%$, with standard deviations lower than 20\%. The MDLs and MQLs were less than $27.6 \mathrm{ng} / \mathrm{L}$ and less than $91.9 \mathrm{ng} / \mathrm{L}$ respectively in aqueous-phase samples, and less than $0.18 \mathrm{ng} / \mathrm{L}$ and less than $0.61 \mathrm{ng} / \mathrm{L}$ respectively in solid-phase samples.

This method was successfully used to detect the ten PCNs and ClPAHs in the water from a river receiving wastewater treatment plant effluent in Beijing. 2-CN, DCN, 9-ClPhe, 2ClAnt 9,10-DClAnt, and 1-ClAQ were detected. In future 
studies, other substituted PAHs with properties similar to those of the target compounds could be added for simultaneous detection after confirmation of their separation with the instrument and column, and calculation of the coefficient of determination of the matrix calibration curve.

Acknowledgements This work was supported by National Natural Science Foundation of China (grant nos 51508552, 51420105012) and the Key Research Program of the Chinese Academy of Sciences (grant no. ZDRW-ZS-2016-5-6).

Publisher's Note Springer Nature remains neutral with regard to jurisdictional claims in published maps and institutional affiliations.

\section{Compliance with ethical standards}

Conflict of interest The authors declare that they have no conflict of interest.

\section{References}

1. Ohura T. Environmental behavior, sources, and effects of chlorinated polycyclic aromatic hydrocarbons. Sci World J. 2007;7:372-80.

2. Espadaler I, Eljarrat E, Caixach J, Rivera J, Marti I, Ventura F. Assessment of polychlorinated naphthalenes in aquifer samples for drinking water purposes. Rapid Commun Mass Spectrom. 1997;11:410-4.

3. Wu M, Li G, Ma J, Xu G, Guo R. Research progress on new type organic contaminants-chlorinated polycyclic aromatic hydrocarbons. Chin J Nat. 2010;32:217-23.

4. Bhatia AL, Tausch H, Stehlik G. Mutagenicity of chlorinated polycyclic aromatic compounds. Ecotoxicol Environ Saf. 1987;14:4855.

5. Pinto M, Rebola M, Louro H, et al. Chlorinated polycyclic aromatic hydrocarbons associated with drinking water disinfection: synthesis, formation under aqueous chlorination conditions and genotoxic effects. Polycycl Aromat Compd. 2014;34:356-71.

6. Johnsen S, Gribbestad IS, Johansen S. Formation of chlorinated PAH - a possible health hazard from water chlorination. Sci Total Environ. 1989;81:231-8.

7. Eljarrat E, Caixach J, Jimenez B, Gonzalez MJ, Rivera J. Polychlorinated naphthalenes in sediments from the Venice and Orbetello lagoons, Italy. Chemosphere. 1999;38:1901-12.

8. Pizzini S, Piazza R, Cozzi G, Barbante C. Simultaneous determination of halogenated contaminants and polycyclic aromatic hydrocarbons: a multi-analyte method applied to filter-feeding edible organisms. Anal Bioanal Chem. 2016;408:7991-9.

9. Li F, Jin J, Tan D, et al. High performance solid-phase extraction cleanup method coupled with gas chromatography-triple quadrupole mass spectrometry for analysis of polychlorinated naphthalenes and dioxin-like polychlorinated biphenyls in complex samples. J Chromatogr A. 2016;1448:1-8.

10. Mahmood A, Malik RN, Li J, Zhang G. Congener specific analysis, spatial distribution and screening-level risk assessment of polychlorinated naphthalenes in water and sediments from two tributaries of the River Chenab, Pakistan. Sci Total Environ. 2014;485: 693-700.

11. Kannan K, Imagawa T, Blankenship AL, Giesy JP. Isomer-specific analysis and toxic evaluation of polychlorinated naphthalenes in soil, sediment, and biota collected near the site of a former chloralkali plant. Environ Sci Technol. 1998;32:2507-14.

12. Shiraishi H, Pilkington NH, Otsuki A, Fuwa K. Occurrence of chlorinated polynuclear aromatic hydrocarbons in tap water. Environ Sci Technol. 1985;19:585-90.

13. Gao ZY, Jiang WS, Sun D, et al. Chlorination for efficient identification of polycyclic aromatic hydrocarbons by liquid chromatography-mass spectrometry. Talanta. 2010;81:48-54.

14. Oyler AR, Liukkonen RJ, Lukasewycz MK, Cox DA, Peake DA, Carlson RM. Implications of treating water containing polynuclear aromatic hydrocarbons with chlorine - a gas chromatographic-mass spectrometric study. Environ Health Perspect. 1982;46:73-86.

15. Oyler AR, Liukkonen RJ, Lukasewycz MT, Heikkila KE, Cox DA, Carlson RM. Chlorine disinfection chemistry of aromatic compounds. polynuclear aromatic hydrocarbons: rates, products, and mechanisms. Environ Sci Technol. 1983;17:334-42.

16. Nilsson UL, Ostman CE. Chlorinated polycyclic aromatic hydrocarbons - method of analysis and their occurrence in urban air. Environ Sci Technol. 1993;27:1826-31.

17. Tillner J, Hollard C, Bach C, Rosin C, Munoz JF, Dauchy X. Simultaneous determination of polycyclic aromatic hydrocarbons and their chlorination by-products in drinking water and the coatings of water pipes by automated solid-phase microextraction followed by gas chromatography-mass spectrometry. J Chromatogr A. 2013;1315:36-46.

18. Ma J, Horii Y, Cheng JP, et al. Chlorinated and parent polycyclic aromatic hydrocarbons in environmental samples from an electronic waste recycling facility and a chemical industrial complex in China. Environ Sci Technol. 2009:43:643-9.

19. Ishaq R, Naf C, Zebuhr Y, Broman D, Jarnberg U. PCBs, PCNs, $\mathrm{PCDD} / \mathrm{Fs}$, PAHs and Cl-PAHs in air and water particulate samples patterns and variations. Chemosphere. 2003;50:1131-50.

20. Qiao M, Qi WX, Liu HJ, Qu JH. Simultaneous determination of typical substituted and parent polycyclic aromatic hydrocarbons in water and solid matrix by gas chromatography-mass spectrometry. J Chromatogr A. 2013;1291:129-36.

21. Marti I, Ventura F. Polychlorinated naphthalenes in groundwater samples from the Llobregat aquifer (Spain). J Chromatogr A. 1997;786:135-44.

22. Vinzelberg G, Schwarzbauer J, Littke R. Groundwater contamination by chlorinated naphthalenes and related substances caused by activities of a former military base. Chemosphere. 2005;61:770-82.

23. Helm PA, Jantunen LM, Ridal J, Bidleman TF. Spatial distribution of polychlorinated naphthalenes in air over the great lakes and airwater gas exchange in Lake Ontario. Environ Toxicol Chem. 2003;22:1937-44.

24. Environment Canada. Ecological screening assessment. Polychlorinated naphthalenes. 2011. https://www.ec.gc.ca/eseees/835522FE-AE6C-405A-A729-7BC4B7C794BF/CNs_SAR_ En.pdf.

25. Vallecillos L, Pocurull E, Borrull F. Influence of pre-treatment process on matrix effect for the determination of musk fragrances in fish and mussel. Talanta. 2015;134:690-8. 